\title{
The UK pilot home zone programme: emerging thoughts and
}

\section{lessons}

\section{Biddulph}

This paper reviews the key lessons emerging from the process of implementing 14 pilot home zone schemes in the UK. It discusses the origin of the concept and reviews the recent interest in home zones in the UK. It briefly reviews the Government's commitment to providing an appropriate legislative and policy context and also funding for the implementation of the concept. It then introduces the pilot schemes and reviews the lessons and debates emerging from the process of both planning and designing the pilot projects. Finally, the article reviews what is now being done to promote the concept to a wider audience and encourage its wider implementation.

\section{INTRODUCTION: WHAT IS A HOME ZONE?}

A home zone is a quiet residential street where the living environment clearly predominates over any provision for vehicles. It is an environment where the design of the spaces between homes provides space for both through-traffic and parking, but where the wider needs of residents are also fully accommodated. This is achieved by adopting approaches to street design, landscaping and highway engineering that control how vehicles move without restricting significantly the number of vehicular movements.

In a home zone, people share what would formerly have been the carriageway and pavements, and if it is well-designed, vehicles can travel at a maximum speed that is only a little faster than walking pace (less than $10 \mathrm{mph}$ ). This then means that other things can be introduced into the street, including, for example, areas for children to play, larger gardens or planting including street trees, cycle parking, and facilities such as seats where residents can meet.

\section{EARLY INITIATIVES AND THE EARLY SCHEMES}

Home zones emerged in the Netherlands during the early 1970s. Their success and popularity resulted in the idea being widely adopted throughout Europe. The Netherlands alone has about 6500 schemes, while the idea has also been popular in countries like Denmark, Germany and Sweden. Initially the concept became disseminated to an English-speaking audience via the publications of the Royal Dutch Touring Club who publicised and explained the then new Dutch regulations for home zone (or woonerfen) design. ${ }^{1}$ More recently, British practitioners have relied on guidance for home zone design provided in Dutch highway design guidelines which are published in English ${ }^{2}$ and also commentary about erf treatments, where home zone design approaches are being adopted in non-residential areas. ${ }^{3}$

\section{EARLY INITIATIVES IN THE UK}

In the UK the first scheme adopting principles similar to those seen in a home zone seems to be The Brow in Runcorn which was developed in 1969 by Runcorn Development Corporation. Following this scheme county councils produced highway design guidance that included advice about shared surfaces which could be used in the development of mews courts. ${ }^{4,5}$ As a result of these innovations the then Departments of Environment and Transport produced their own Design Bulletin 32: Residential Roads and Footpaths ${ }^{6}$ which included cautious advice suggesting that in certain limited situations shared surface treatments might be acceptable in new housing schemes.

During the 1980s urban regeneration funds allowed a number of local authorities to alter existing streets to introduce characteristics similar to the home zone. Most notable in this respect are Worthington Street in Leicester (Fig. 1), schemes like Rhymney Street in Cardiff and the Scotch Terraces in Llwynypia, Rhondda. At the same time the occasional new housing scheme has also used shared-surface access, including for example Oldbrook in Milton Keynes, while schemes like the social housing scheme for the Old Royal Free Hospital in

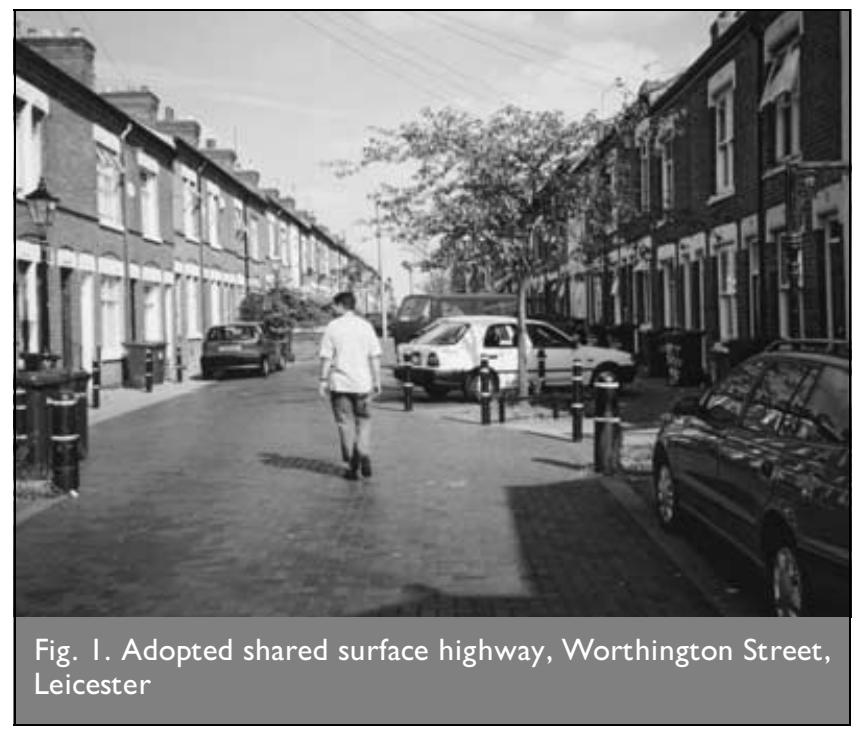




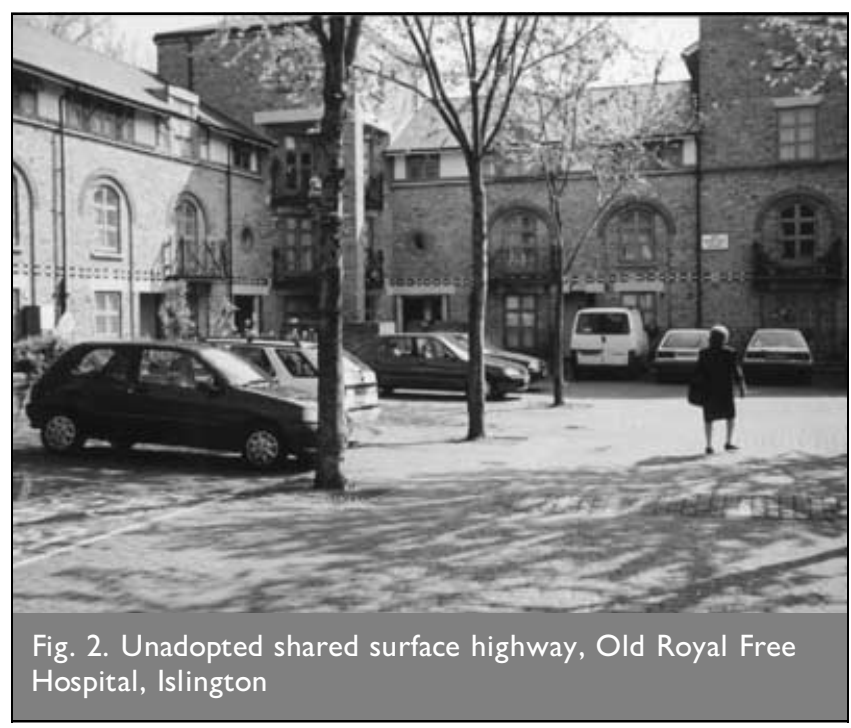

Islington (Fig. 2) illustrate what is possible where highways in a scheme are not adopted by the local authority, and more innovative, people-friendly and attractive layout ideas have been considered. ${ }^{7}$

\section{RECENT HOME ZONE INITIATIVES}

The academic and road safety campaigner Barbara Preston coined the term 'home zone' in the early 1990s. In response to the high level of child pedestrian casualties in residential streets, she proposed changing the law so that in certain 'home zone' streets drivers would bear the burden of proof for any crashes involving pedestrians that they were involved in.

Although Preston's idea of a purely legal basis for a home zone was not taken forward, the term was revived by the Children's Play Council and Transport 2000 in the late 1990s as a translation of the Dutch concept of a woonerf (literally 'living yard'). These two organisations, with support from the Child Accident Prevention Trust and others, called for Dutch-style home zones to be introduced on a pilot basis in the UK, along with funding and legislation to allow local authorities to set them up. ${ }^{8}$

Transport 2000 also supported local residents' groups that wanted to become a home zone including, for example, groups such as Methleys Neighbourhood Action in Leeds, which turfed over a street during the 1996 August Bank Holiday. Other key supporters included Peterborough MP Helen Brinton, whose Home Zones Bill gained the support of over 230 MPs from across the Parliamentary spectrum. This growth in support coincided with the newly-elected Government's wish to develop a new transport strategy, starting with the 1998 Transport White Paper-arguably the first tangible expression of Government support.

\section{RECENT GOVERNMENT COMMITMENT TO THE HOME ZONE}

Since the late 1990s the home zone concept has appeared repeatedly in relevant policy documents, it has been the subject of a pilot project initiative, and it has been given a legal basis.

\section{I. Policy initiatives}

The Government supports the home zone concept because it is thought that

(a) home zone treatments in existing residential areas will help make those areas more popular and attractive, and might also assist in improving community relations as people use the street space more; this could assist urban regeneration and community development

(b) the shift of emphasis away from car use might encourage people to consider walking or cycling, especially where home zones are introduced in areas served by direct paths or cycle routes to shops or other facilities

(c) home zones may encourage adults to let their children play outside as their fear of traffic accidents is reduced; this in turn should allow children to be more active and subsequently improve their health

(d) where they are well-designed, residential areas may become more attractive; this is because there is more space for common home zone features referred to earlier such as street trees, larger gardens, street facilities such as seating, tables or toddlers' play equipment or even some public art.

\subsection{New legislation}

The Government's commitment to the development of home zones has subsequently developed with new provisions for home zones featuring in section 268 of the Transport Act $2000^{9}$ which came into force in February 2001 for England and Wales, and section 74 of the Transport (Scotland) Act 2001 which received royal assent in January $2001 .{ }^{10}$

The legislation was introduced prior to the formal evaluation of the pilot projects, demonstrating the responsiveness of Government to the oft-repeated concern that local authorities would not widely implement schemes without the legal status of the highways being clear.

In England and Wales, section 268 of the Transport Act provides powers to designate home zones by means of orders for both use and speed. A use order permits 'the use of a road for purposes other than passage' such as, for example, children playing or adults chatting. This use, however, is on the condition that a person does not '(a) wilfully ... obstruct the lawful use of a road by others, or (b) ... use a road in a way which would deny reasonable access to premises situated on or adjacent to the road.' A speed order allows the local traffic authority to introduce measures for reducing the speed of motor vehicles or cycles to below a speed specified in the order. Although no speed limit is indicated, home zones should support a design speed of about $10 \mathrm{mph}$. In Scotland, section 74 of the Transport (Scotland) Act allows the local authority to designate a highway as a home zone on the grounds of improving safety, environmental preservation, and so as to allow improved facilities for users of the roads who are not using motor vehicles.

\subsection{The pilot programme}

Nine home zone pilot projects have been introduced in England and Wales, one in Northern Ireland and four in Scotland. Of these, 13 are in existing streets, while only one is in a new housing development. The English and Welsh pilot projects emerged as a cautious initiative prior to the home zones 
legislation. In fact in A New Deal for Transport: Better for Everyone $^{11}$ the Government stated their view that, with good design, many of the objectives of (Continental-style) home zones could be achieved using existing legislation. As a result they invited authorities to bid for home zone pilot status, with the Government looking to monitor the schemes and find out just what could be achieved. In Scotland four pilot projects were established in November 1999. The Scottish Executive were also of the view that the pilot projects should be used to explore what could be achieved under existing Scottish legislation before it committed itself to changes in the relevant law.

The pilots are exploring how local schemes might be planned and designed, while their formal evaluation by the Transport Research Laboratory in England and Wales and 'Land Use Consultants' in Scotland, will also consider, among other things, how successful the schemes are at reducing vehicular speeds and whether the residents use the street space more and are more satisfied with the resulting environments when compared to the previous street environments. Table 1 lists the current home zone pilot projects.

\section{FINANCIAL ASSISTANCE FOR HOME ZONES}

Home zones are expensive. Very roughly speaking pilot home zones currently being progressed in the UK are costing about £200 000-300 000 per street (based on interviews in March/ April 2001). This itself is very roughly equivalent to $£ 1000$ per metre of road.

In England many previous projects have paid for their work through funding gained from a Local Transport Plan bid. In 2001 money raised from this source ranged from $£ 100000-$ 350000 for home zone schemes. Where they have been involved, housing associations and societies have also funded part of the work themselves, and in particular 'off highway' work. In addition some of the projects (most notably Northmoor in Manchester (Fig. 3)) have also gained funding from being part of a broader Single Regeneration Budget initiative.

There has now been an extension to the funding of home zones in England following the Government's announcement of $£ 30$ million being made available through what has become known as the Home Zones Challenge. Announced in April 2001, the Challenge aims to accelerate the growth of the home zone programme. Being an initiative for a specific time frame with a

- Ealing Five Roads, West Ealing

- Holmewood, Lambeth

- Methleys, Leeds

- Magor, Monmouthshire

- Northmoor, Manchester

- Nobel Road, Nottingham

- New England, Peterborough

- Morice Town, Plymouth

- Cavel Way, Sittingbourne, Kent

- Long Streets, Belfast

- Alexander Terrace, Tillydrone, Aberdeen

- Gorgie and Dalry, Edinburgh

- Dundee Royal Infirmary, Dundee

- Ormlie, Thurso

Table I. The 14 home zone pilot projects

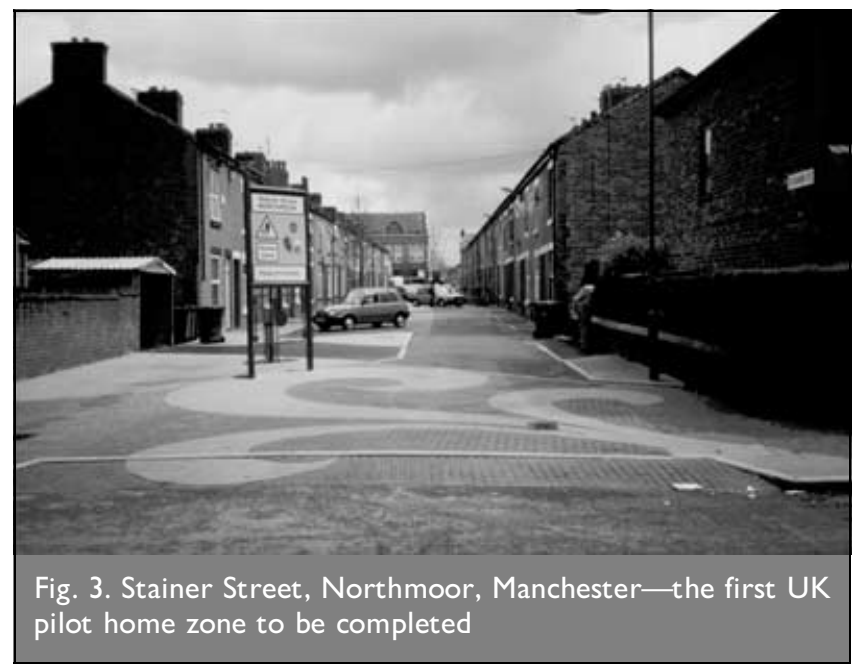

fixed budget, there are still questions being asked about how home zones will be funded in the future, and whether previously used funding mechanisms will constitute sustainable sources in the long term.

\section{LESSONS FROM THE PILOTS: PLANNING AND DESIGN PROCESSES}

The pilot projects referred to above have been introduced into a range of settings and involve schemes covering a range of areas. Research into these pilots ${ }^{7}$ has made it possible to identify a number of general themes that could form the basis for a continuing evaluation of Home Zone Challenge schemes in the future.

(a) Definition of home zone. The notion of a home zone remains vague for many people. Techniques for successfully disseminating information about the concept need to be found for both professionals and residents alike.

(b) A scheme must develop as a result of dialogue with local people. Some of the pilot projects emerged as a result of community pressure for improvements to local traffic conditions, while in more disadvantaged areas schemes have tended to be led by the local authority. In all cases local authorities (or other lead agencies) need to adopt community planning techniques which fully engage local people in the process of planning and designing a scheme.

(c) Use visualisations and 'mock-ups' of the scheme. People have tended to understand a proposed pilot scheme most effectively where a mock-up of the scheme, in the street and for a day, has been used. This was an innovation originally tried in Manchester.

(d) Be creative but realistic. There is limited evidence to suggest that well-meaning council officers or facilitators have used community planning exercises without fully considering the usefulness of their respective outputs. Creative but realistic schemes need to evolve as a result of using only techniques useful for the given task. Participants should also be informed about the likely budget available for the scheme and the cost of features being considered. Collectively, such features of a process should help to manage the expectations of residents.

(e) Learn from others. A number of schemes benefited from making visits to home zone schemes either in the Netherlands or even now to schemes in the UK. 
(f) Have a dedicated member of staff committed to home zone schemes. Schemes have benefited from having a lead person in the local authority or regeneration agency who has been identified as the coordinator for the project. Future schemes also need to consider how to effectively manage and coordinate the various stages of the work.

(g) Use facilitators. Independent facilitators have been used in a number of schemes for both planning and design. Some local authorities in particular pointed out the benefit of not being so closely involved, so that residents do not begin to think the scheme is being imposed by the council. In some cases the engineers have also asked architects and landscape architects to work with residents and create the initial ideas for a scheme. This is because their schemes are often more creative or interesting.

(h) Have fun. Many of the schemes have used social events as a mechanism for helping people reimagine their street; to draw attention to, or get support for the project; or to help people in getting to know their neighbours. The role of home zones as a vehicle for community development needs to be more fully understood, while ideas about how to have fun planning a home zone also need to be disseminated.

(i) Timing and momentum. Home zones can take a long time to plan and develop, and residents have commented that evidence of progress during the project (e.g. some road closures or speed humps) helps people appreciate that something is happening.

(j) Professional versus resident expectations. Established community groups typically work quite informally, over a long period of time and with a greater emphasis on fun and wide public engagement. In contrast, professionals can be more goal-directed, trying to complete projects efficiently over a short period. As a result, tensions between the two groups can emerge. It is necessary to explore ways of developing awareness of this issue and consider practices that help to overcome the problem. Early meetings could, for example, involve agreeing a set of shared outcomes, outlining formal procedures and indicating key deadlines for such work.

\section{LESSONS FROM THE PILOT PROJECT DESIGNS}

Some general design principles for home zones are illustrated in Fig. 4. A number of points related to the design of the pilots can also be made. ${ }^{7}$

(a) The position of engineers. In some pilot projects engineers have deliberately elected not to be the professionals initially deciding the form of home zone schemes. This is because home zones require a multi-disciplinary input which needs to consider aspects of a street's urban form and landscape as well as patterns of informal activity. Engineers have tried to involve architectural, landscape and urban designers more fully than in more traditional work so that a richer scheme emerges. Such an approach reflects a view held by other professionals that some engineers tend to rely too heavily on tried and tested approaches to street design, rather than actively seeking out and considering new ideas.

(b) Scheme justification. Most of the schemes were initially justified on the grounds that they would reduce and/or slow down through-traffic. A small number were justified as environmental improvements. None of the schemes were justified on safety grounds alone. Road safety statistics were actually regarded by some as creating a false impression. It was noted that many unfriendly, unloved, ugly, noisy, polluted streets have an excellent safety record simply because no pedestrians use them.

(c) Parking. The most pressing concern for residents is parking. There are two main issues arising under this heading: providing adequate levels in secure locations close to people's homes and being able to control levels of parking by non-residents.

(d) Shared surfaces. Many schemes are aiming to achieve an area of shared surface, although for most this was considered an expensive option for the whole area. Despite the Continental experience, most projects do not regard shared surfaces as a prerequisite for establishing a home zone.

(e) Routeing alignment. Most schemes are planning to use echelon parking to introduce chicanes into the road system. In most areas speed reduction is also planned using more traditional calming techniques such as route narrowing, speed humps or tables and the introduction of vertical elements such as seating, planters and trees.

$(f)$ Children's play. The introduction of formal play facilities is being actively considered in a number of pilots, although this is almost exclusively confined to play areas located away from the highway. In general, the objective of formally endorsing play in the street has not been popular.

(g) Seating. Seating is also a controversial addition to some home zone pilots, especially where it is thought that 'undesirable' people might come in to the area, or the seating might encourage youths to loiter. In some places seating might be introduced on a temporary basis.

(h) Soft landscaping. Tree planting is a common feature of many schemes. In some pilots children were encouraged to do the planting in the hope that it would reduce vandalism, although this has had limited success.

(i) Hard landscaping. Most of the new hard landscaping being introduced into the schemes seems to be associated with traffic-calming measures. In this respect a number of schemes are using printed asphalt instead of paving to reduce costs and achieve the same paving effect.

(j) Signage. Currently there is no official home zone sign and local authorities have to design and get a separate permission for any sign that they might want to use. The lack of a legal sign for home zones has caused problems for the pilots. Government is currently looking into the possibility of adopting the 'standard' sign for home zones which is seen in other parts of Europe.

(k) Public art. A number of schemes have used artists to devise signs, gateways, and mosaics. Funding for this involvement has come from local authority community arts initiatives, Single Regeneration Budget funds or bids to the National Lottery.

(l) Underground services. The need to locate and accommodate existing service lines has been a significant factor in the design of all schemes, and most have been planned without affecting the existing situation. The need for very clear advice from relevant utility and telecommunication companies about the location of services has been a problem, as a lot of information is imprecise. 


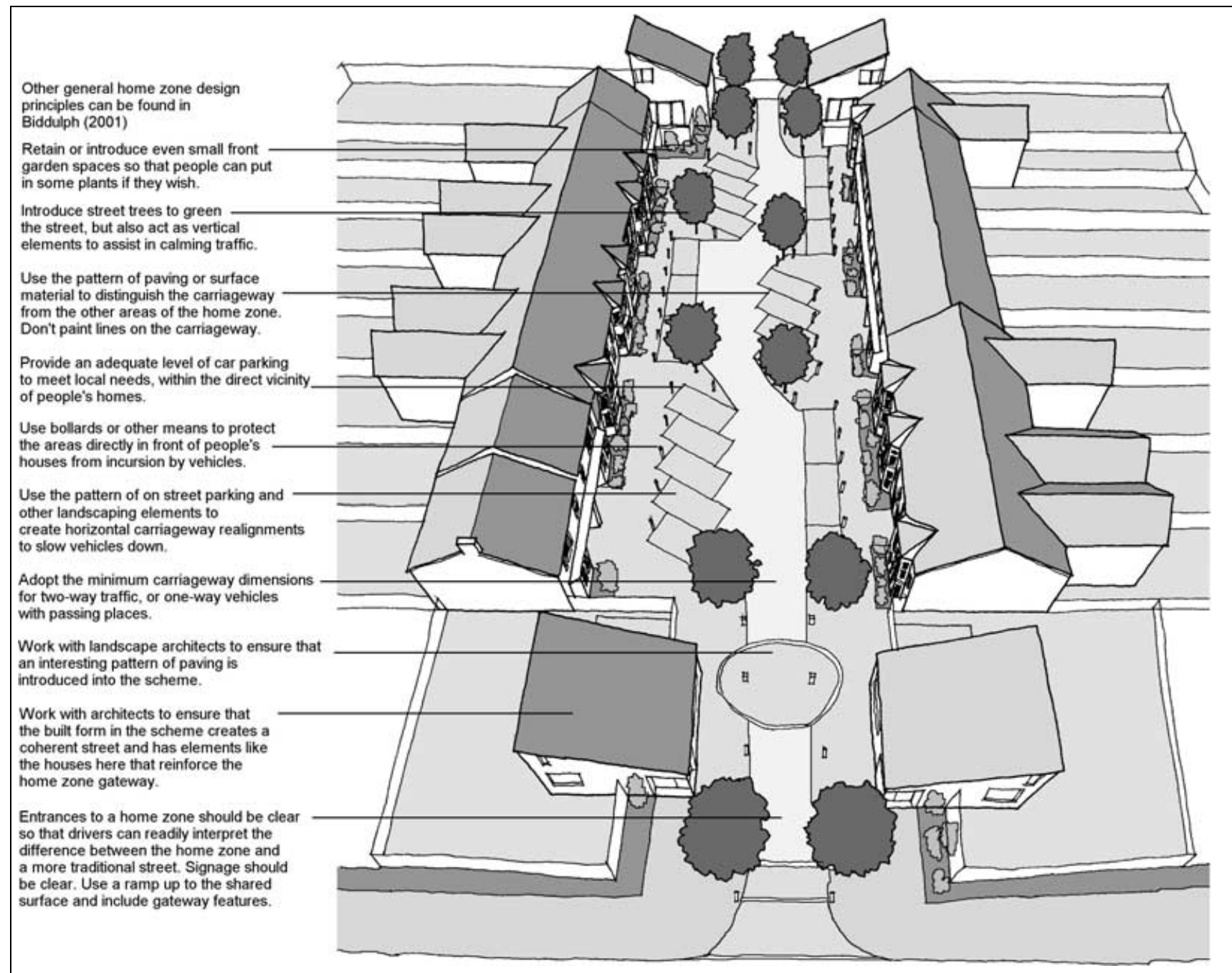

Fig. 4. Some home zone design principles

(m) Lighting. New lighting is being considered in a number of schemes, and white rather than yellow lighting is being used to produce better colour definition, which allows features including paving to be highlighted more clearly at night.

\section{WIDER PROMOTION OF HOME ZONES IN THE UK}

Government support for home zones has been critical to their implementation nationally, but this adoption has also been assisted by initiatives taken by an additional range of professional and non-governmental organisations. The Children's Play Council and Transport 2000 have actively lobbied for the concept and provided a publication ${ }^{8}$ and a video which have been widely used by both professionals and residents' groups. These two organisations continue to provide critical support to the home zones initiative in a variety of ways, but in particular by supporting the publication of Home Zone News and by managing the national home zone website (www. homezonenews.org.uk).

Individuals and professional groups have also started to consider the nature of advice and guidance that should be given to professionals and communities about how to plan, design and manage future schemes. This has resulted in a number of related initiatives. Transport $2000^{12}$ has published a guide to creating 'living streets' while Timebank has also published a Changing Streets Pack. ${ }^{13}$ The Institution of Civil Engineers has produced a brief publication Returning Roads to Residents ${ }^{14}$ which provides advice on street agreements, parking and environmental improvements, while with the Urban Design Alliance the Institution has also published a related guide looking at how streets might be more effectively managed. ${ }^{15}$ Ben Hamilton-Baillie from Sustrans was sponsored by the Winston Churchill Memorial Trust to visit and report on European and Scandinavian home zone schemes. ${ }^{16}$ The Institute of Highway Incorporated Engineers is currently working to produce design and engineering guidance for a professional audience and with a focus on new build schemes. ${ }^{17}$ The Joseph Rowntree Foundation also has a publication providing good practice guidance on how to both plan and design both retrofit or new build home zone schemes. ${ }^{7}$

With the implementation of schemes supported by the Home Zone Challenge funding, we can expect the amount of information available about actual schemes to increase. What concerns some, however, is that schemes might become 'halfbaked' glorified traffic-calming schemes because real home zones will be too expensive or the concept might remain misunderstood. 


\section{REFERENCES}

1. Royal Dutch Touring Club. Woonerf. RDTC, The Hague, 1977.

2. CROW ASVV recommendations for traffic provisions in built-up areas. CROW, The Netherlands, 1998.

3. CROW. Van Woonerf Tot Erf. CROW, The Netherlands, 1989.

4. Essex County Council. A Design Guide for Residential Areas. Essex County Council, Chelmsford, 1973.

5. Cheshire County Council. Design Aid Housing: Roads. Cheshire County Council, Chester, 1976.

6. Department of the Environment and Department of TransPORT. Design Bulletin 32 Residential Roads and Footpaths: layout considerations. HMSO, London, 1977.

7. BiddulPh M. Home Zones: a planning and design handbook. Policy Press, Bristol, 2001.

8. Children's Play Council. Home Zones: Reclaiming residential streets. National Children's Bureau, London, 1997.

9. HM Government. Transport Act 2000. The Stationery Office, London, 2000.
10. HM Government. Transport Act (Scotland) 2001. The Stationery Office, Edinburgh, 2001.

11. Department of the Environment, Transport and the Regions. A New Deal for Transport: Better for Everyone. HMSO, London, 1998.

12. TRANSPORT 2000. Living Streets: a guide to cutting traffic and reclaiming street space. Transport 2000, London, 2000.

13. TimeBank. Changing streets pack. Also at www.timebank. org.uk

14. Institution of Civil Engineers. Returning Roads to Residents: A practical guide to improving your street. ICE, London, 2000.

15. Institution of Civil Engineers/Urban Design Alliance. Designing Streets for People: An investigation into the way we plan, design, manage and maintain our streets. ICE, London, 2000.

16. Hamilton-BAILliE B. Home zones-reconciling people, places and transport. Available at www.gsd.harvard.edu/loebfell/ sponsored/homezones/index.htm

17. Institute of Highway and Incorporated Engineers. Home Zones: Design Guidelines. IHIE, London (in press).

Please email, fax or post your discussion contributions to the secretary by 3 January 2003: email: kathleen.hollow@ice.org.uk; fax: +44 (0)20 7799 1325; or post to Kathleen Hollow, Journals Department, Institution of Civil Engineers, I-7 Great George Street, London SWIP 3AA. 